\title{
Professor William Jack 'Dick' Whittington 2nd February 2009
}

We are very sad to report the death of Dick who was Senior Editor of the Journal of Agricultural Science (Cambridge) from 1991 to 1998.

Dick's appointment as Senior Editor had been the culmination of a number of meetings and related matters. Prior to 1991 the Journal had been based at Cambridge but, with the closure of the Department of Applied Biology together with the sale of the nearby Plant Breeding Institute to the private sector (the Department and Institute had long-established links that had been of considerable benefit to the Journal), the board had given much thought to the future of the Journal.

A key consideration was that, were the Journal to be moved elsewhere, it should be located somewhere with an excellent research reputation in the Agricultural Sciences. The University of Nottingham Sutton Bonington Campus was identified and Dick (as the recently retired Professor of Agricultural Botany) was approached formally in May 1990 with a view to taking over as Senior Editor in January 1991.

Dick approached his duties with characteristic enthusiasm and professionalism. The move to Sutton Bonington had required a considerable amount of effort and it is to his credit that all appeared to go smoothly. The Journal continued its success under his guidance and a number of innovations were introduced, including going 'on-line' in 1996.

All who came into contact with Dick were impressed with his overall commitment to maintain the reputation and quality of the Journal; when he retired in December 1998, he left it in a healthy state although he still continued to take an active interest and offer valuable advice to the newly appointed Senior Animal Editor! 